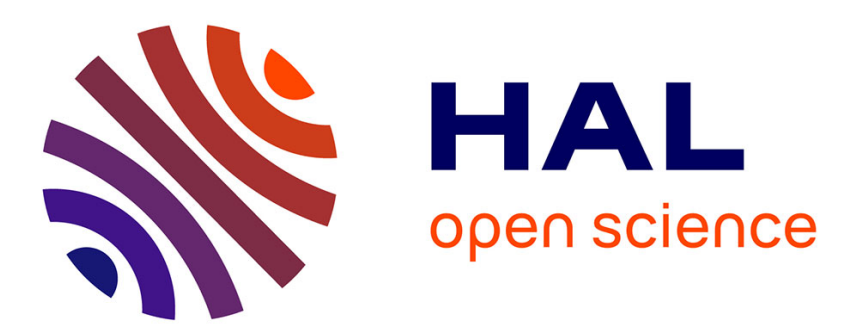

\title{
Waveform Optimization using RF Pulse Signal on Voltage-Doubler Broadband Rectenna
}

\author{
Viet-Duc Pham, Hakim Takhedmit, Laurent Cirio
}

\section{To cite this version:}

Viet-Duc Pham, Hakim Takhedmit, Laurent Cirio. Waveform Optimization using RF Pulse Signal on Voltage-Doubler Broadband Rectenna. IEEE Journal of Radio Frequency Identification, In press, 10.1109/jrfid.2020.3039878 . hal-03121979

\section{HAL Id: hal-03121979 \\ https://hal.science/hal-03121979}

Submitted on 26 Jan 2021

HAL is a multi-disciplinary open access archive for the deposit and dissemination of scientific research documents, whether they are published or not. The documents may come from teaching and research institutions in France or abroad, or from public or private research centers.
L'archive ouverte pluridisciplinaire HAL, est destinée au dépôt et à la diffusion de documents scientifiques de niveau recherche, publiés ou non, émanant des établissements d'enseignement et de recherche français ou étrangers, des laboratoires publics ou privés. 


\title{
Waveform Optimization using RF Pulse Signal on Voltage-Doubler Broadband Rectenna
}

\author{
Viet-Duc Pham, Hakim Takhedmit, and Laurent Cirio
}

\begin{abstract}
In this paper, the DC-output improvement of a broadband rectenna has been demonstrated using pulse signal. The pulse waveform is optimized by varying its duty cycle as well as its modulation frequency. The rectenna operating from 1.6 to 2.8 GHz is characterized experimentally with low/medium RF power and different loads. The optimized waveform has a duty cycle that varies between 1 and $20 \%$ for a modulation frequency between 1 and $6 \mathrm{MHz}$. The results show that the DC voltage and the efficiency are improved over the frequency band of interest, particularly for frequencies below $1.8 \mathrm{GHz}$ and those above 2.6 GHz. The DC-output improvement, compared to the 1-tone signal, is characterized by the calculation of voltage/efficiency gain. High gain values are experimentally obtained: close to 14 $\mathrm{dB}$ at $1.675 \mathrm{GHz}$ and $-20 \mathrm{dBm} \mathrm{RF}$ power. The voltage gain is greater than $0 \mathrm{~dB}$ for low $(3 \mathrm{k} \Omega)$ and high $(100 \mathrm{k} \Omega)$ loads. At 2.4 GHz and for a low load of $3 \mathrm{k} \Omega, 4-\mathrm{dB}$ gain is measured at - 30 $\mathrm{dBm}$. For a load of $100 \mathrm{k} \Omega$, the efficiency goes from $8.3 \%$ for the 1-tone to about $74.7 \%$ for the optimized waveform, at $-15 \mathrm{dBm}$ RF power level.
\end{abstract}

Index Terms-broadband rectifier, power optimized waveform, RF pulse, wireless power transmission.

\section{INTRODUCTION}

$\mathrm{N}$ OWADAYS, Internet of Things (IoTs) are developed dramatically and gathering significant interest in research. IoTs demand a high density of sensors and electronics devices and require the maximum autonomy as possible. To supply power to the sensors and electronics devices, for now, traditional chemical batteries are still used. This can cause environmental pollution as well as time consuming while recharge or replace them. To address the issue of replacing completely battery, WPT (Wireless Power Transmission) is one of the most useful ways as it can convert RF power to DC power wirelessly to supply the power to wireless electronics devices and sensors. One of the biggest problems of WPT is that at small RF power levels, the RF-todc conversion efficiency and DC voltage of the energy harvester such as rectenna (antenna + rectifier) are considerably low [1]. To increase the DC voltage and/or the efficiency at very low power, optimizing the waveforms can be a useful solution [1-11]. On the other hand, the electronics devices and sensors should be able to harvest the energy from ambiance with different RF signals with several frequency ranges such as GSM, UMTS, Wi-Fi and LTE2600/4G.

V-D. Pham, H. Takhedmit and L. Cirio are with ESYCOM, Univ. Gustave Eiffel, CNRS UMR 9007, F-77454 Marne-la-Vallée, France (email: hakim.takhedmit@u-pem.fr)
Different type of large band or multi-band rectennas and their designing procedures are presented in [12-20]. A dual band rectenna operating at 2.4 and $5.8 \mathrm{GHz}$ [13] and rectenna arrays [14-15] are designed to enhance RF energy harvesting applications.

A dual-port triple-band L-Probe rectenna is designed and optimized for ambient RF energy harvesting using GSM-900, GSM-1800, and UMTS-2100 bands [16]. For the power densities higher than $500 \mu \mathrm{W} / \mathrm{m}^{2}$, this rectenna can reach an efficiency of greater than $40 \%$ and an output DC voltage of more than $600 \mathrm{mV}$. In [17], 16- and 81-element broadband bow-tie rectenna arrays screen printed on a cotton T-shirt is presented. The rectenna-array is dedicated for harvesting power in the range $4-130 \mu \mathrm{W} / \mathrm{cm}^{2}$ between 2 and $5 \mathrm{GHz}$. An RF-powered Body Area Network, based on $915 \mathrm{MHz}$ and 2.4 $\mathrm{GHz}$ rectennas, with multiple power receivers, based on fullytextile antennas is studied in [18].

In [19], the authors use an optimization algorithm to automatically take the output voltage as feedback for system calibration. Compared to the rectifier built by foundryprovided zero-threshold transistors, the tunable-threshold rectifier experimentally shows 4-dB improvement in input sensitivity. In [20], the authors present a compact $2.45 \mathrm{GHz}$ broadband rectenna using the grounded coplanar waveguide. A voltage-doubler broadband rectenna, operating from 1.6 to $2.8 \mathrm{GHz}$, is proposed in [12]. It shows nearly-constant performances, with efficiency higher than $15 \%$ at $-15 \mathrm{dBm}$ $\mathrm{RF}$ power level, over the frequency band of interest. It is a promising solution for ambient energy harvesting. In this paper, it is shown how the optimized pulse waveform has allowed improving the performances of this structure over the frequency band of interest.

When applying different types of waveforms such as CW, OFDM, white noise and chaotic signals to a single diode rectifier, the output DC voltage is often improved as the PAPR (Peak-to-Average Power Ratio) of the input signal increases [1-3]. The single-diode rectifier has its efficiency gain improved up to $5 \mathrm{~dB}$ at $-15 \mathrm{dBm}$ by using multisine signals compared to CW [4]. In [5], for the rectifier designed and optimized at $5.8 \mathrm{GHz}, 2$-tone signal shows a power gain of approximately $7 \mathrm{~dB}$ at $-11 \mathrm{dBm}$. Besides, a multistage rectifier optimized at $2.4 \mathrm{GHz}$ shows similar results with a voltage gain of $2.7 \mathrm{~dB}$ at $-4 \mathrm{dBm}$ [6]. In [7], multisine signal is used to improve the range and readability of RFID tags. In [8-10], RF pulse signal allows to improve the output DC voltage of the shunt-mounted diode and voltage-doubler rectifiers at $2.4 \mathrm{GHz}$ 
when the duty cycle and the load resistances vary. The rectifier efficiency is increased from $20 \%$ (1-tone) to approximately $55 \%$ (RF pulse) at a high RF power level of 10 $\mathrm{dBm}$. In [11], the authors demonstrate that with the 3-tone Tx waveforms, the IM3 carrier generated by the nonlinear tag can be enhanced by $4 \mathrm{~dB}$. Under the same PAPR, the harvested DC power with the excited IM3 is noticeably higher than that obtained with the 2-tone waveform.

For the first time, in this paper, the performance improvement of a broadband rectenna, operating from 1.6 to $2.8 \mathrm{GHz}$, using optimized RF pulse signal is addressed. We are aiming for low and medium RF power levels, ranging from -30 to $0 \mathrm{dBm}$. We have optimized the duty cycle and the modulation frequency of the input waveform so as to fit as much as possible to the rectenna, taking into account its non-linear behavior. Indeed, the RF-to-dc conversion circuit is inherently non-linear. The optimization is done around an operating point, for a certain RF power level, an operating frequency and an output DC load. When it deviates from this operating point, the performances of the rectenna degrade. In this work, we will show how the optimization of the modulated pulse waveform applied on a broadband rectenna allows improving the performances from this point of view.

The RF pulse signal with its characteristics and output-voltage ripple issue will be presented in section II. Section III presents the broadband rectenna operation and the achieved prototype. The waveform optimization algorithm, the measurement setup and results in terms of output DC voltage, efficiency and voltage/efficiency gain are presented in section IV. The conclusion is given in section $\mathrm{V}$.

\section{RF PULSE SIGNAL}

\section{A. RF pulse signal}

RF pulse signal is generated by a modulation method as displayed in Fig. 1. Continuous sinewave with frequency $f_{c}$ is modulated by a square pulse with frequency $f_{m}\left(f_{c} \gg f_{m}\right)$. The shape of RF pulse depends on the shape of periodic square signal. Within one period, the time at high level is defined as $T_{\beta}$.

The duty cycle of RF pulse signal is calculated by the following equation:

$$
\beta(\%)=100 \cdot \frac{T_{\beta}}{T_{m}}
$$

where $T_{m}=1 / f_{m}$.

The PAPR of the signal is calculated as follows:

$$
\text { PAPR }=10 \log _{10}\left(\frac{\max \left(x(t)^{2}\right)}{\left\langle x(t)^{2}\right\rangle}\right)
$$

where $x(t)$ is the time domain waveform of the signal and $\langle x(t)\rangle$ is the average value of $x(t)$ [2]. The maximum power of the signal is related to its average power and duty cycle as follows:

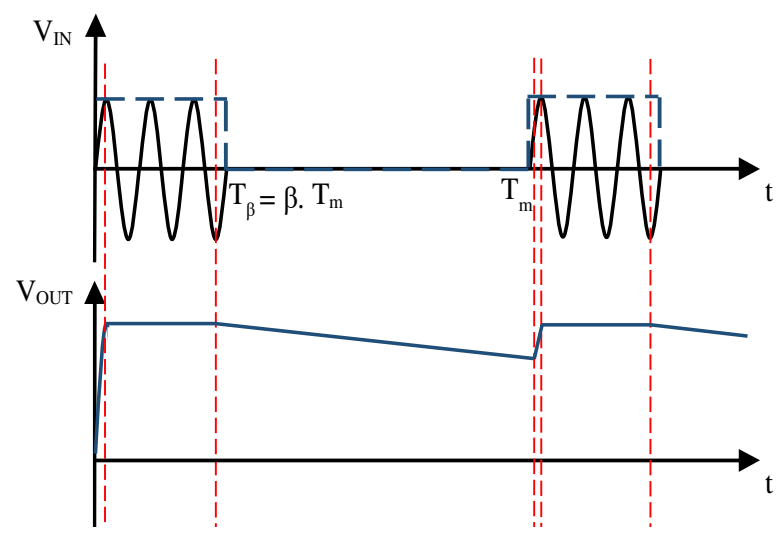

Fig. 1. Input and output voltages in time domain.

$$
\max \left(x(t)^{2}\right)=100 \frac{\left\langle x(t)^{2}\right\rangle}{\beta}
$$

Higher PAPR means that the variation of the signal in time domain is more substantial. As the PAPR of continous sine wave $(\beta=100 \%)$ is $3 \mathrm{~dB}[2]$, one has that:

$$
\operatorname{PAPR}(\beta)=3+10 \log _{10}\left(\frac{100}{\beta}\right)
$$

Consider that $\beta \geq 1 \%$, the maximum PAPR that can be reached is $23 \mathrm{~dB}$ as $\beta=1 \%$. It decreases to $3 \mathrm{~dB}$ when $\beta$ increases to $100 \%$. The relation between $\beta$ and PAPR can be seen from equation (4). A comparison between RF pulse signal and multisine signal shows that the number of subcarriers of multisine signal has to be high to obtain the same PAPR of RF pulse signal. For example, a multi-sine signal with 64-subcarriers and a RF pulse with a duty cycle of $1.58 \%$ have the same PAPR of $21 \mathrm{~dB}$.

\section{B. Ripple of output DC voltage}

The ripple of the output DC voltage is one of the issues of traditional rectifiers when dealing with RF pulse signals. For a $\mathrm{CW}$ signal of frequency $f_{c}$, the ripple of the output voltage is reduced by choosing the time constant of the low-pass filter $\left(\mathrm{R}_{\mathrm{L}}\right.$ and $\left.\mathrm{C}\right)$. That time constant must be significantly greater than the period of the input RF signal, like shown by the equation (5)

$$
\tau=R_{L} \cdot \mathrm{C} \gg T_{c}=\frac{1}{f_{c}}
$$

For RF pulse signal, the design of this filter requires more attention. The carrier frequency targeted in this work is a few $\mathrm{GHz}$ while the modulation frequency is a few MHz. The role of the output filter is to eliminate the fundamental frequency and the harmonics. It transmits the DC component without ripple. Fig. 1 shows the waveforms of the input and output voltages.

In order to reduce the ripple of the output voltage during the discharge phase $\left(T_{\text {off }}\right)$, the capacitor $\mathrm{C}$ must be increased so as to obtain a greater time constant:

$$
T_{o f f}=\left(1-\frac{\beta}{100}\right) \cdot T_{m}=\frac{(1-\beta / 100)}{f_{m}} \ll \tau=R_{L} \cdot C
$$


Indeed, the load $\mathrm{R}_{\mathrm{L}}$ represents the input impedance of the device to be supplied, it cannot be modified easily. The ripple of the output voltage depends particularly on the modulation frequency, the duty cycle, the capacitor $\mathrm{C}$ of the low-pass filter and the load $\mathrm{R}_{\mathrm{L}}$. From equation (3) and considering a constant RF power level, the input voltage applied to the diodes during the period of time where the RF pulse is turned on increases when the duty cycle decreases. The output DC voltage will continue to increase as the duty cycle decreases. This is true when considering the time period between 0 and $T_{\beta}$ as sufficient to completely charge the capacitor C. In this case, the maximum output voltage will be obtained for the smallest duty cycle value. However, if the duty cycle becomes too small, the output capacitor $\mathrm{C}$ will not be able to charge at its maximum voltage. Resultantly, there would be an optimum duty cycle value which allows maximizing the output DC voltage while maintaining the minimum ripple of the DC voltage. This optimum depends on the output low-pass filter components $\left(\mathrm{R}_{\mathrm{L}}\right.$ and $\left.\mathrm{C}\right)$, the carrier frequency, the modulation frequency, the RF power level and the other components of the rectenna (lumped and distributed elements).

\section{BROADBAND RECTENNA}

Fig. 2a shows the broadband rectenna, which contains the receiving antenna and rectifying circuits.

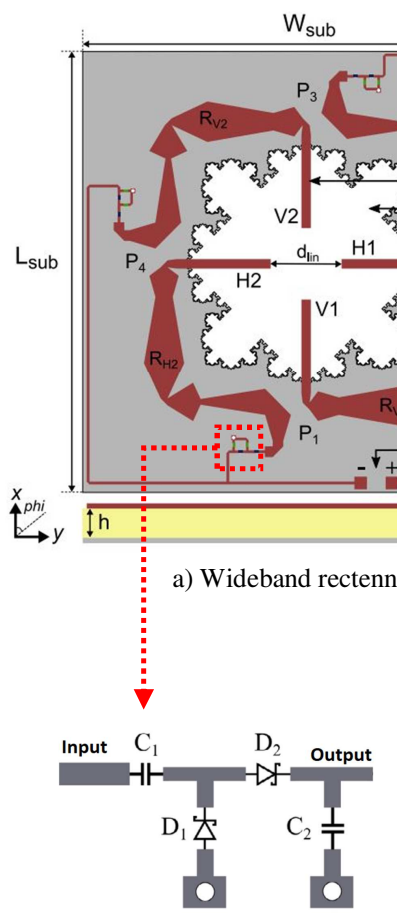

b) Layout of the rectifier
Microstrip lines and rectifier circuits Fractal slot ground
plane

\section{Microstrip line} Fractal slot - Ground plan

\section{$\leftrightarrow$ Schottky diode}

(11) Capacitor

- Via hole

- DC recombination lines DC outputs

Substrate
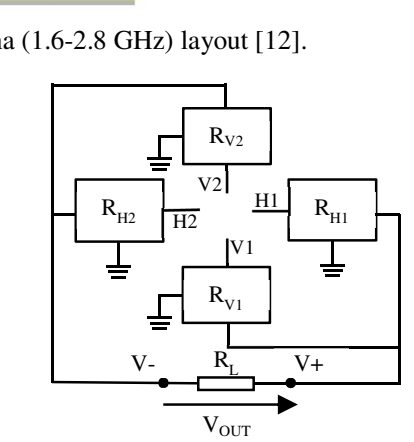

c) DC interconnection scheme

Fig. 2. Wideband rectenna with rectifying part

The rectifying part contains 4 identical rectifiers denoted as $\mathrm{R}_{\mathrm{H} 1}, \mathrm{R}_{\mathrm{H} 2}, \mathrm{R}_{\mathrm{V} 1}$ and $\mathrm{R}_{\mathrm{V} 2}$. The layout of the voltage-doubler topology rectifier is shown in Fig. 2b. The DC interconnection of the different rectifiers is depicted in Fig. 2c. Each rectifier

contains an input HF filter, a DC low-pass filter, 2 Schottky diodes configured as a voltage doubler and a via-hole connected to the ground plane for the DC path current. It provides higher output DC voltage compared to singlemounted diode rectifiers. Due to the demand of harvesting RF energy over a wide frequency band, the input-impedance matching network of the rectifier is designed as a micro-strip non-uniform transmission lines (NUTL), which can provide broadband impedance matching. To get a compact rectenna, S-shaped filter geometry is used as the input impedance matching network. The Schottky diode SMS7630-079LF from Skyworks is chosen. Its low biasing voltage property fills the requirement for small power operation [12]. The rectifiers are associated as shown in Fig. 2c and share the same output load. Rectifiers $\mathrm{R}_{\mathrm{H} 1}$ and $\mathrm{R}_{\mathrm{V} 1}$ are connected in parallel as well as $\mathrm{R}_{\mathrm{H} 2}$ and $R_{V 2}$. They deliver the positive and negative $D C$ voltages, respectively. This DC interconnection topology is more robust with respect to the power imbalances that there may be between the horizontal and vertical accesses. These 2 subarrays, which are power balanced, are then connected in series with the resistive load $R_{L}$ to enhance the output $D C$ voltage.

The reflection coefficient $S_{11}$ of the rectifying circuit has been characterized experimentally from 1.6 to $2.8 \mathrm{GHz}$, for different RF power levels between -30 and $-10 \mathrm{dBm}$, by a step of $5 \mathrm{~dB}$ (Fig. 3). The resistive output load is fixed at $3 \mathrm{k} \Omega$. The $\mathrm{S}_{11}$ is characterized for a $\mathrm{CW}$ input waveform. It is improved as the RF power level increases as shown in Fig. 3. Moreover, the $S_{11}$ when using a pulse waveform should be improved in comparison with that obtained when using a $\mathrm{CW}$ waveform. Indeed, the instantaneous power when the pulse is turned on is greater and it increases when the duty cycle decreases. Consequently, the $S_{11}$ should be improved when the duty cycle of the pulse waveform decreases.

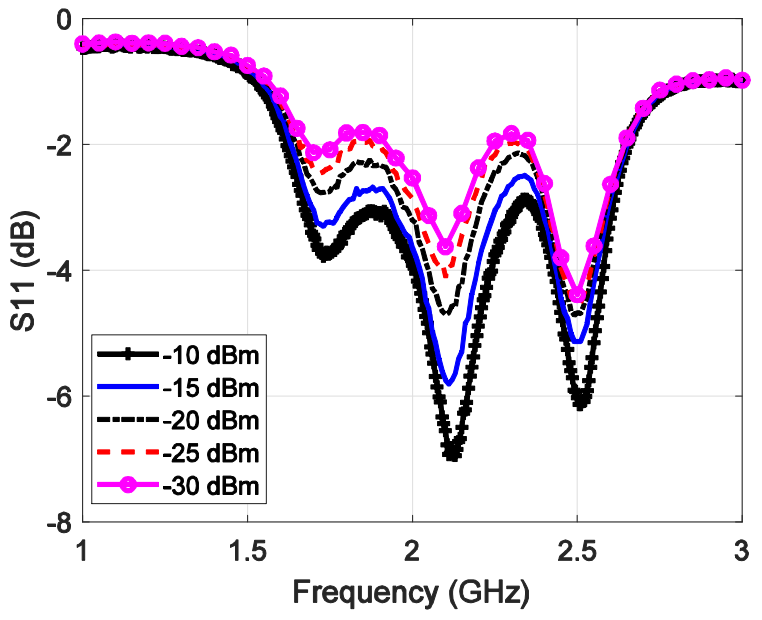

Fig. 3. Reflection coefficient $\left(S_{11}\right)$ of the rectifying circuit against frequency, for different RF power levels $\left(\mathrm{R}_{\mathrm{L}}=3 \mathrm{k} \Omega\right)$.

The proposed antenna is a wideband fractal-shaped slotted ground antenna (SGA). Fig. 4 displays the $S_{11}$ of the antenna over the frequency range from 1 to $3 \mathrm{GHz}$. All accesses are well matched and the reflection coefficient is less than $-10 \mathrm{~dB}$ over the frequency band of interest from 1.6 to $2.8 \mathrm{GHz}$. By 
using a differential-feed topology, the receiving power amount is increased. The fractal SGA is fed by a DP-DF (DualPolarized and Differential-feed) lines composed of four $50-\Omega$ micro-strip transmission lines etched on the bottom side along $x$ and $y$ accesses and denoted $\mathrm{H}_{1}, \mathrm{H}_{2}, \mathrm{~V}_{1}$ and $\mathrm{V}_{2}$, for linear horizontal and vertical polarizations [12].

Fig. 4 also shows the measured and simulated gains of the antenna in the frequency range from 1 to $3 \mathrm{GHz}$. Due to the fabrication and measurement tolerances, there are differences between the simulated and measured curves [12].

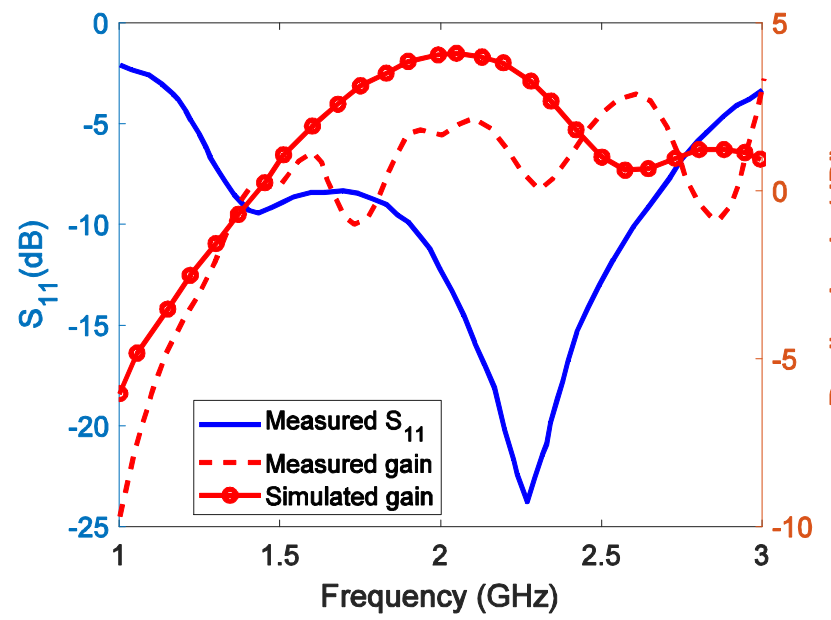

Fig. 4. Reflection coefficient and realized gains of the antenna [12].

The rectenna is printed on a FR4 substrate with the thickness of $1.6 \mathrm{~mm}$. The top view (fractal SGA) and bottom view (micro-strip lines with rectifier array) of the rectenna prototype are displayed in Fig. 5. The dimensions of the rectenna are $140 \times 140 \mathrm{~mm}^{2}$.
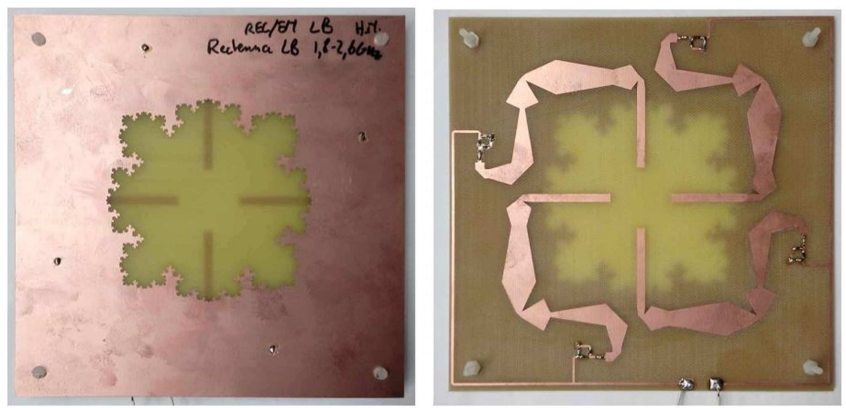

Fig. 5. Top and bottom of the wideband-rectenna prototype [12].

\section{WAVEFORM OPTIMIZATION AND EXPERIMENTAL RESULTS}

\section{A. Waveform optimization}

To maximize the output DC voltage, the pulse-modulated waveform is optimized by varying its frequency $\left(f_{\mathrm{m}}\right)$ as well as its duty cycle $(\beta)$. This optimization is repeated for each set of parameters: carrier frequency, RF power level and output load. The duty cycle makes it possible to vary the PAPR of the input signal and therefore the maximum value of the input voltage. Indeed, when the duty cycle decreases, the PAPR increases. The modulation frequency, combined with the value of the duty cycle, is used to vary the period of time when the pulse is turned on. For a given duty cycle value, when the modulation frequency increases, the duration when the pulse is turned on decreases. Also, the bandwidth of the input signal depends on the modulation frequency. The duty cycle ranges from 1 to $99 \%$ and the modulation frequency ranges from 1 to $6 \mathrm{MHz}$. The automated measurement setup, shown in figures 6 and 7 , is used for waveform optimization and experiments.

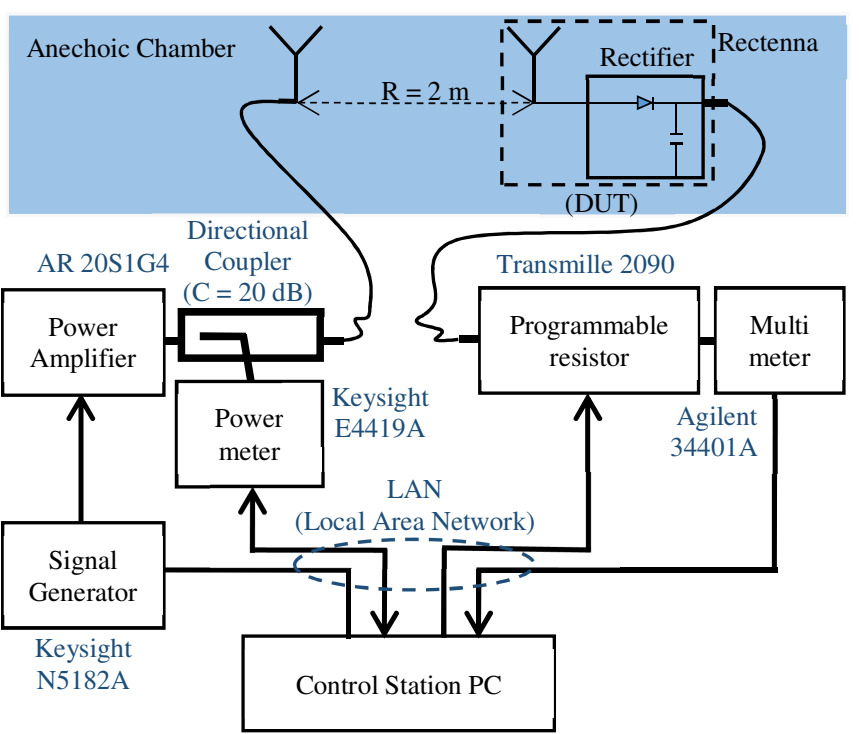

Fig. 6. Schematic of the measurement setup.

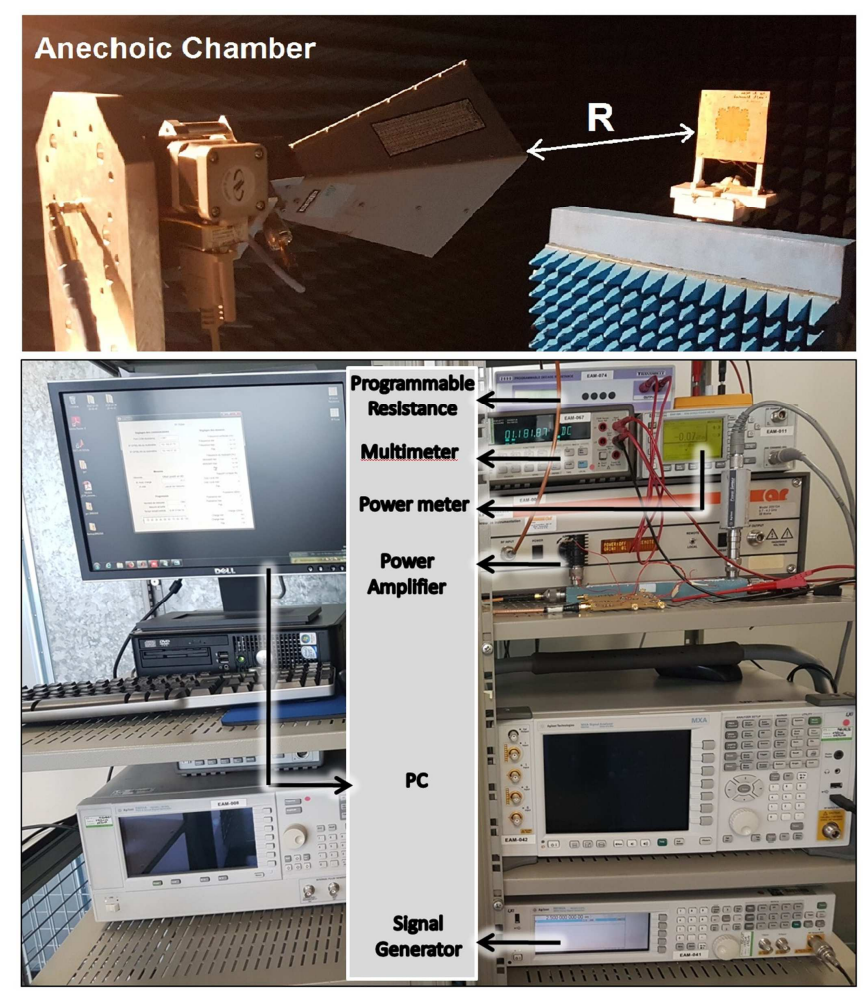

Fig. 7. Photograph of the measurement setup.

The RF pulse signal is created using Matlab program, which controls the output of signal generator (Keysight N5182A). 
Matlab program sets the pulse wave with different values of duty cycle, modulation frequency and carrier frequency. The maximum modulation frequency of the signal generator is 125 MHz. In order to satisfy the sampling condition, the modulation frequency in this work is limited to $6 \mathrm{MHz}$.

To control RF power level received by the rectenna, which is also the average power of the signal received by the rectenna, Matlab program handles the calculation using Friis transmission formula and sets the appropriate values of the power-amplifier (AR 20S1G4) gain and also the generator output power. The power meter (Agilent E4419A) measures the transmitted power to the horn antenna and compares it to the pre-calculated value. Several measurements are required to get the targeted power level. When the pre-calculated power is applied to the horn antenna, which is controlled by the motorcontroller, the RF signal is transmitted to the rectenna. Then, programmable resistor (Transmille 2090) sets the resistor load value. The multi-meter (Agilent 34401A) measures the output $\mathrm{DC}$ voltage and sends it to the main program. These loops are repeated until all the measurements are done. In anechoic chamber, the rectenna is placed at the distance of $\mathrm{R}=2 \mathrm{~m}$ from the horn antenna. The horn antenna radiates $45^{\circ}$ linearly-polarized waves. The capacitor of $10 \mathrm{nF}$ is connected at the output of the rectenna to eliminate the voltage ripple. According to the equation (6), the minimum time constant $\mathrm{R}_{\mathrm{L}}$.C is $30 \mu \mathrm{s}$ (as $\mathrm{R}_{\mathrm{L}}=3 \mathrm{k} \Omega$ ). On the other hand, the maximum ripple is obtained for the minimum value of $f_{\mathrm{m}}$ and $\beta$ (1 $\mathrm{MHz}$ and $1 \%$, respectively), which corresponds to a maximum value of $T_{\text {off }}$ of $0.99 \mu \mathrm{s}$. The equation (6) is then satisfied for all measurements.

The RF power level is calculated by using the Friis transmission equation. The RF-to-dc conversion efficiency of the rectenna is calculated as follows:

$$
\eta(\%)=100 \frac{P_{\text {out }}}{P_{r}}=100 \frac{V_{\text {out }}{ }^{2}}{R_{L}} \frac{1}{P_{r}}
$$

where $\mathrm{V}_{\text {out }}$ is the output DC voltage, $\mathrm{R}_{\mathrm{L}}$ is the load resistance. On the other hand, the voltage/efficiency gain of the RF pulse compared to the 1-tone signal is calculated by the formula:

$$
G_{P}=20 \log _{10}\left(\frac{V_{\text {out }}^{\text {RF pulse }}}{V_{\text {out }}^{1-\text { tone }}}\right)=10 \log _{10}\left(\frac{\eta_{R F} \text { pulse }}{\eta_{1-\text { tone }}}\right)
$$

This gain makes it possible to give the improvement of the DC output due to the use of the optimized waveform, in comparison with the 1-tone signal. In all comparative measurements made in this work, the average RF power level is kept constant.

Figures 8 to 11 show the output DC voltage as a function of the duty cycle, from 1 to $99 \%$, for different values of modulation frequency (1, 3 and $6 \mathrm{MHz})$. Two RF power levels $(-20$ and $-25 \mathrm{dBm})$ and two load values $(3$ and $100 \mathrm{k} \Omega)$ were considered. The carrier frequency is $2.4 \mathrm{GHz}$. Also, the results obtained for a 1-tone signal are given as a reference and for comparison. As can be seen, as the duty cycle increases the output DC voltage of RF pulse signal decreases to reach the value of voltage obtained using 1-tone signal. For a duty cycle of $99 \%$, all the curves reach the voltage value obtained with $\mathrm{CW}$. As the duty cycle increases, the PAPR and also the maximum input voltage decrease. This explains the decrease in terms of DC voltage as a function of the duty cycle. Furthermore, it can be noted that the voltage curves obtained for 3 and $6 \mathrm{MHz}$ of modulation frequency and for low values of duty cycle are lower compared to those obtained for 1 $\mathrm{MHz}$. This is mainly due to the decrease in the duration when the RF pulse is turned on and which becomes insufficient to fully charge the output capacitor (DC filter). It is also because the spectral occupancy of the input signal considerably increases for small values of the duty cycle when the modulation frequency increases, which degrades the DC output.

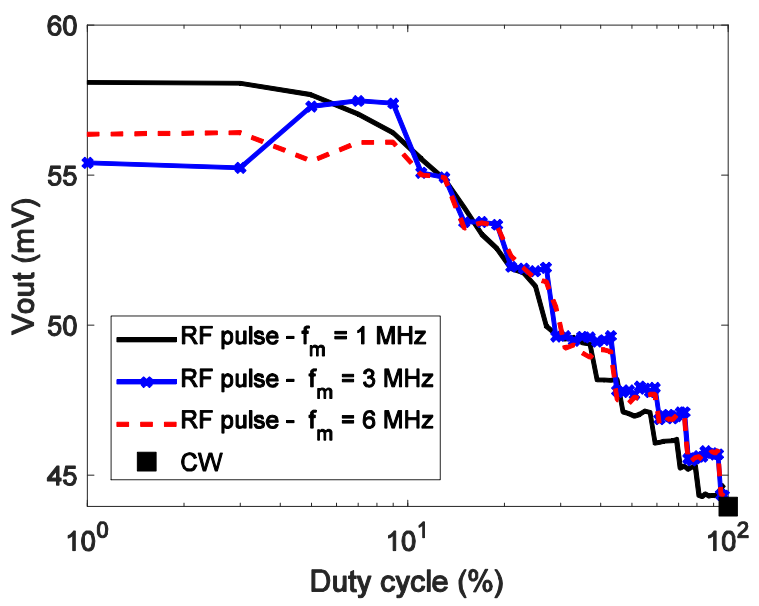

Fig. 8. DC voltage of RF pulse and CW signals versus duty cycle $\left(R_{L}=3 \mathrm{k} \Omega\right.$, $\left.P_{R F}=-20 \mathrm{dBm}\right)$.



Fig. 9. DC voltage of RF pulse and CW signals versus duty cycle $\left(R_{L}=3 \mathrm{k} \Omega\right.$, $\left.P_{\mathrm{RF}}=-25 \mathrm{dBm}\right)$.

Indeed, when the duty cycle decreases and at the same time the modulation frequency increases, the period of time during which the pulse is turned on is not large enough to charge the output capacitor to its maximum voltage. The different curves meet for higher duty cycle values, from around $10 \%$. This behavior is found in figures 8 to 11 for both power levels (-25 and $-20 \mathrm{dBm}$ ) and both load values (3 and $100 \mathrm{k} \Omega$ ). At -20 $\mathrm{dBm}$ and for a load of $3 \mathrm{k} \Omega$, the maximum voltage of $58 \mathrm{mV}$ is obtained at $1 \mathrm{MHz}$ of modulation frequency and $1 \%$ of duty 
cycle. The voltage obtained for 1-tone signal is $44 \mathrm{mV}$. The improvement in the DC output due to the optimized waveform corresponds to a voltage gain of $2.4 \mathrm{~dB}$.

For a load of $100 \mathrm{k} \Omega$ and a RF power of $-25 \mathrm{dBm}$, a maximum voltage of $210 \mathrm{mV}$ is obtained for a modulation frequency of 1 $\mathrm{MHz}$ and a duty cycle of $1 \%$. The reference voltage obtained for a CW signal is only $80 \mathrm{mV}$. A gain of $8.4 \mathrm{~dB}$ is thus obtained under these conditions. On the other hand, the maximum voltage obtained for 3 and $6 \mathrm{MHz}$ is only $135 \mathrm{mV}$.

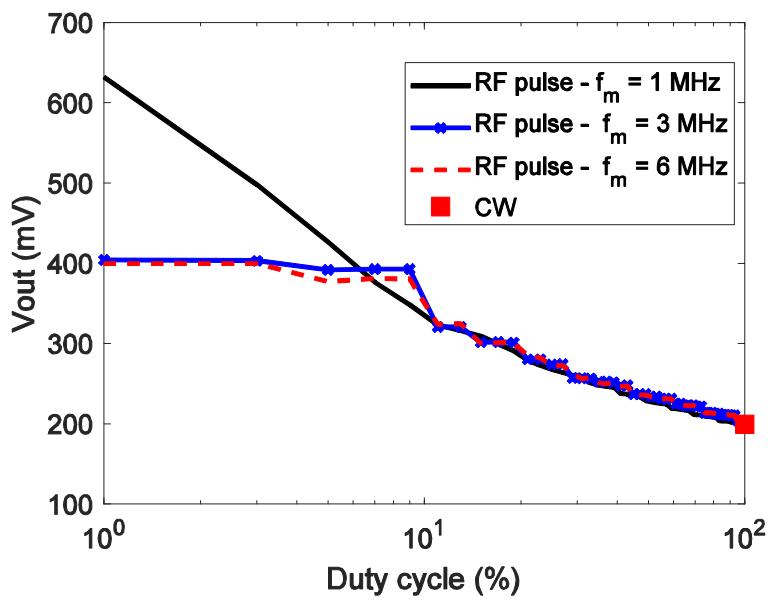

Fig. 10. DC voltage of RF pulse and CW signals versus duty cycle $\left(\mathrm{R}_{\mathrm{L}}=100\right.$ $\left.\mathrm{k} \Omega, \mathrm{P}_{\mathrm{RF}}=-20 \mathrm{dBm}\right)$.

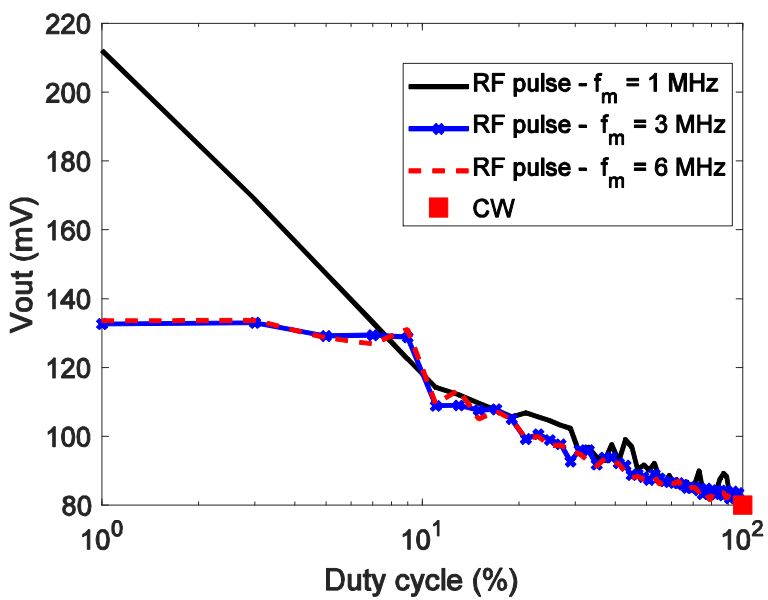

Fig. 11. DC voltage of RF pulse and CW signals versus duty cycle $\left(\mathrm{R}_{\mathrm{L}}=100\right.$ $\left.\mathrm{k} \Omega, \mathrm{P}_{\mathrm{RF}}=-25 \mathrm{dBm}\right)$.

At $2.4 \mathrm{GHz}$, and for -25 and $-20 \mathrm{dBm}$ of RF power level, the pulse signal with $f_{\mathrm{m}}=1 \mathrm{MHz}$ always shows better DC output with small duty cycle values. The maximum output DC voltage is achieved at $1 \%$. The same optimization steps are repeated for all the frequencies ranging from 1.6 to $2.8 \mathrm{GHz}$. For each frequency of interest, the maximum DC voltage is retained. The optimization of the pulse waveform involves the choice of its modulation frequency as well as its duty cycle.

We have performed the simulations of the RF pulse signal in frequency domain with three modulated frequencies: $1 \mathrm{MHz}, 3$ $\mathrm{MHz}$ and $6 \mathrm{MHz}$ and the carrier frequency of $2.4 \mathrm{GHz}$ using Matlab software. The simulation results show that when the modulation frequency increases and/or the duty cycle decreases, the pulse width decreases. In the meantime, the spectrum occupancy is increased, which means that the power concentration around the carrier frequency is smaller. This is the case with modulated frequency of $3 \mathrm{MHz}$ and $6 \mathrm{MHz}$, compared to $1 \mathrm{MHz}$. For that reason, with small values of duty cycle, the DC output voltages at $3 \mathrm{MHz}$ and $6 \mathrm{MHz}$ are lower than that at $1 \mathrm{MHz}$. When the duty cycle becomes higher, the difference in frequency domain between RF pulse signals with the different modulated frequency values becomes smaller. Therefore, from $10 \%$ of duty cycle, the DC outputs are nearly the same for the different values of the modulation frequency.



Fig. 12. Waveform optimization algorithm.

This optimization follows the algorithm shown in Fig. 12. The parameters are chosen based on the characteristics of the input waveforms and the rectenna. For RF pulse signal, there is only 2 parameters: duty cycle and modulated frequency. The duty cycle is varied from 1 to $99 \%$. Due to characteristic of our signal generator N5182 Keysight Technology, the maximum value of modulation frequency is $125 \mathrm{MHz}$, we choose the maximum value of $f_{\mathrm{m}}$ is $6 \mathrm{MHz}$ to have a sufficient number of sampling points. The minimum of $f_{\mathrm{m}}$ is set to $1 \mathrm{MHz}$ to satisfy the equation (6) for all measurements with variation of the parameters. Therefore, the modulation frequency takes three values: 1, 3 and $6 \mathrm{MHz}$. The load impedance is chosen as 3 $\mathrm{k} \Omega$ and $100 \mathrm{k} \Omega$. The choice is made because the optimized resistance of the rectifying circuit for $\mathrm{CW}$ signal is $3 \mathrm{k} \Omega$. We have also tested the rectenna with a load sufficiently far from the optimized load resistance. Besides, the carrier frequency is chosen based on the operating frequency of the rectenna from 1.6 to $2.8 \mathrm{GHz}$. The RF power levels are taken from -30 to 0 $\mathrm{dBm}$. One of the objectives of this work is to improve output voltage and the RF-to-dc conversion efficiency of the rectenna under pulse wave excitation and at low and medium RF power levels. Depending on the different parameters: the carrier frequency, the RF power level and the output load, the duty cycle value which allows maximizing the output voltage varies between 1 and $20 \%$. The modulation frequency is kept at $1 \mathrm{MHz}$. 


\section{B. Measurement results}

The optimization procedure of the pulse waveform described in part $\mathrm{A}$ is applied to characterize the rectenna at different frequencies, different RF power levels and different load values. The relevant results are presented in this part and discussed. Figure 13 displays the output DC voltage of the rectenna as a function of the frequency from 1.6 to $2.8 \mathrm{GHz}$. Measurements were made for a $3 \mathrm{k} \Omega$ load and for power levels ranging from -30 to $-10 \mathrm{dBm}$ with a step of $5 \mathrm{~dB}$. The voltage curves obtained with the optimized pulse waveform are systematically compared to those obtained by using the 1tone signal. Similar measurements were made using a load of $100 \mathrm{k} \Omega$.

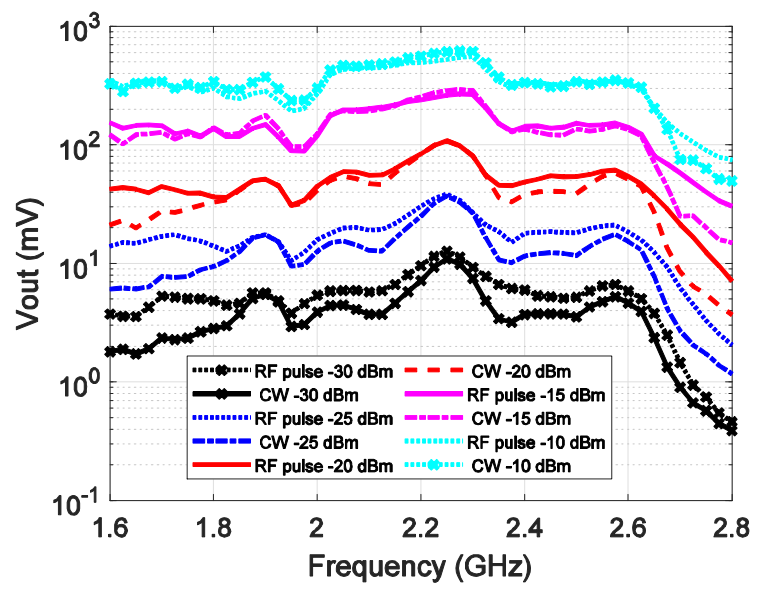

Fig. 13. Output DC voltage of RF pulse and CW signals against frequency for different $R F$ power levels $\left(R_{L}=3 \mathrm{k} \Omega\right)$.

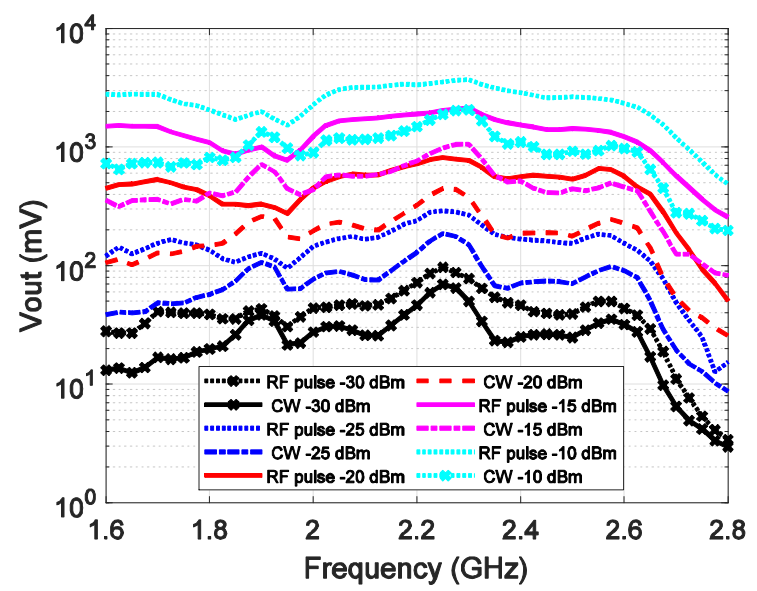

Fig. 14. Output DC voltage of RF pulse and CW signals against frequency for different RF power levels $\left(\mathrm{R}_{\mathrm{L}}=100 \mathrm{k} \Omega\right)$.

The results are presented in Fig. 14. This allows observing the voltage improvement behavior at low and high load resistances, due to the use of optimized waveform. The results show that the output voltage increases as the RF power level increases. The output voltage curves for 1-tone signal decrease slightly for frequencies below $1.8 \mathrm{GHz}$ and above $2.6 \mathrm{GHz}$. For a load of $3 \mathrm{k} \Omega$ and for low power levels down to $-20 \mathrm{dBm}$, the DC voltage is improved on the frequency band of interest. This improvement is greater at frequencies below $1.8 \mathrm{GHz}$ and above $2.6 \mathrm{GHz}$. For powers of -15 and $-10 \mathrm{dBm}$, the improvement is smaller except for frequencies below $1.8 \mathrm{GHz}$ and above $2.6 \mathrm{GHz}$. For a large load of $100 \mathrm{k} \Omega$, the voltage is improved for all power levels and over the frequency band of interest. The differences between the voltage curves obtained for 1-tone and those for optimized waveform are greater for a large load $(100 \mathrm{k} \Omega)$. Indeed, at center of the frequency band (2.2 GHz), DC voltage obtained with RF pulse signal is significantly higher than that of 1-tone signal as it increases from $447 \mathrm{mV}$ to $815 \mathrm{mV}$ at $-20 \mathrm{dBm}$. In the meantime, the efficiency is improved from $5.05 \%$ to $16.78 \%$.

The duty cycles of RF pulse signal required to reach the maximum output DC voltage varies between $1 \%$ and $20 \%$ within the frequency range, regardless the resistance load value. For example, at load value of $3 \mathrm{k} \Omega$, the optimum duty cycles are $10 \%$ and $20 \%$ for the frequency of 1.85 and 2.1 $\mathrm{GHz}$, respectively. For load value of $100 \mathrm{k} \Omega$, it is found that the maximum optimum duty cycle is $15 \%$ for the frequency of $2.125 \mathrm{GHz}$.

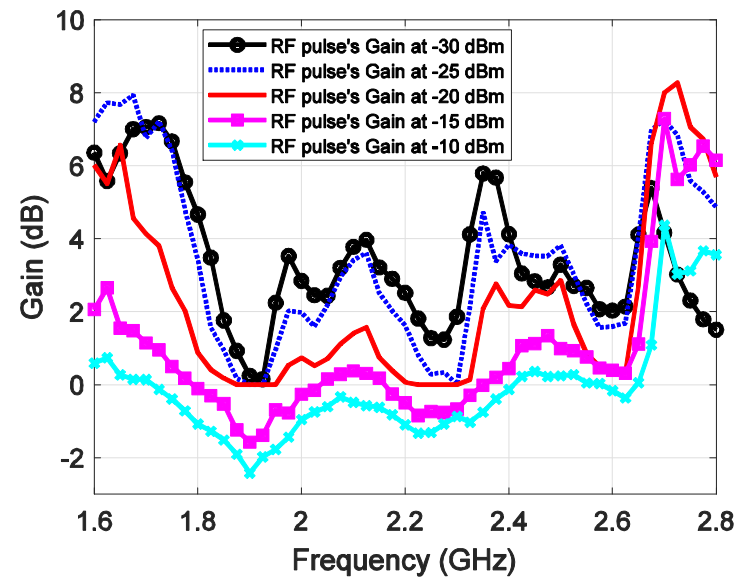

Fig. 15 Voltage/efficiency gain of optimized RF pulse signal against frequency for different RF power levels $\left(R_{L}=3 \mathrm{k} \Omega\right)$.

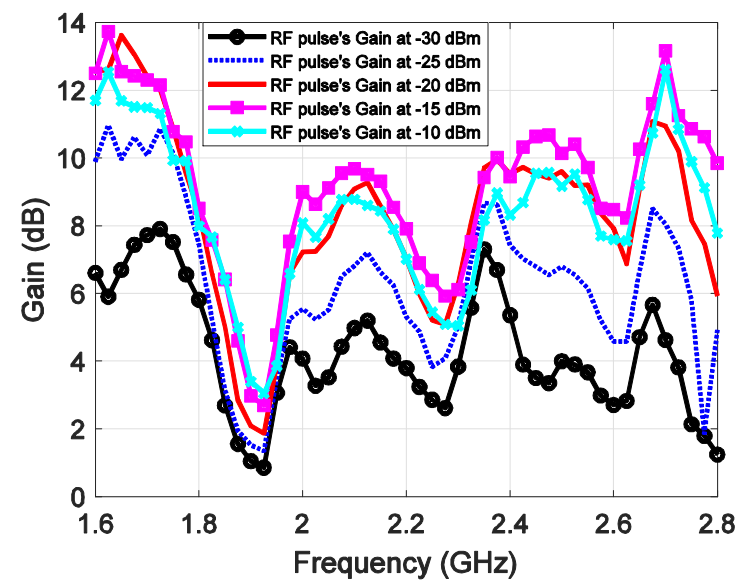

Fig. 16. Voltage/efficiency gain of optimized RF pulse signal against frequency for different RF power levels $\left(R_{L}=100 \mathrm{k} \Omega\right)$. 
The voltage gain is calculated and depicted in figures 15 and 16 as a function of frequency from 1.6 to $2.8 \mathrm{GHz}$. Five RF power levels are considered from -30 to $-10 \mathrm{dBm}$ by a step of $5 \mathrm{~dB}$. In general, the gain is particularly higher for frequencies below $1.8 \mathrm{GHz}$ and above $2.6 \mathrm{GHz}$. In contrast, regardless of the frequency, the gain at $100 \mathrm{k} \Omega$ is better than that at $3 \mathrm{k} \Omega$. The lowest gain is $0.85 \mathrm{~dB}$ at $100 \mathrm{k} \Omega$ and $0 \mathrm{~dB}$ at $3 \mathrm{k} \Omega$. The highest gain recorded for $100 \mathrm{k} \Omega$ is $13.95 \mathrm{~dB}$ at $1.675 \mathrm{GHz}$ and $-20 \mathrm{dBm}$ RF power level, which allows an RF-to-dc conversion efficiency increase from 0.325 to $7.205 \%$. The improvement in two cases are different with more important gain at higher RF power level when resistance load value is $100 \mathrm{k} \Omega$ and vice versa at load value of $3 \mathrm{k} \Omega$, where the best improvement is found at $-30 \mathrm{dBm}$.

Measurements as a function of RF power level, for two different loads ( 3 and $100 \mathrm{k} \Omega$ ), were carried out. The results are presented in figures 17 and 18 .

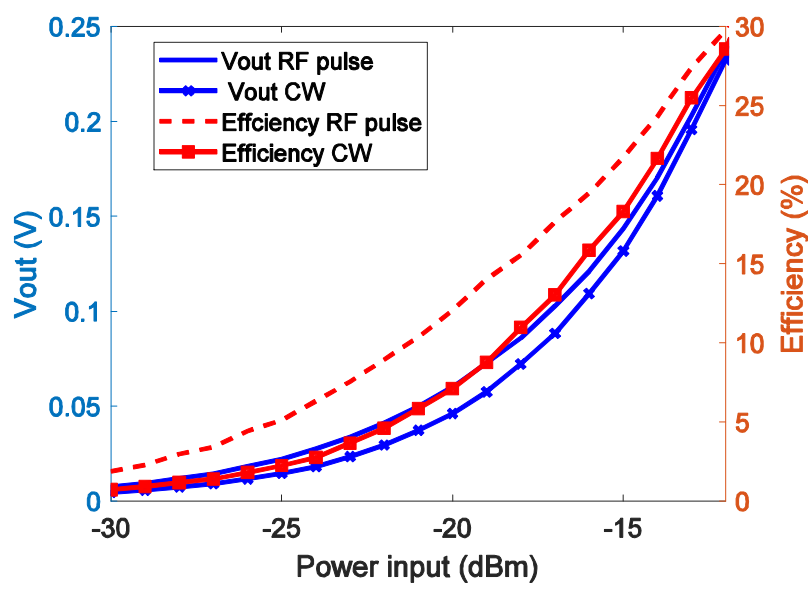

Fig. 17. Output DC voltage and efficiency of RF pulse and CW signals versus $\mathrm{RF}$ power level $\left(\mathrm{R}_{\mathrm{L}}=3 \mathrm{k} \Omega\right)$.



Fig. 18. Output DC voltage and efficiency of RF pulse and CW signals versus RF power level $\left(R_{L}=100 \mathrm{k} \Omega\right)$.

The carrier frequency is fixed to $2.4 \mathrm{GHz}$ and the RF power varies from -30 to $0 \mathrm{dBm}$. For each load value, the voltages and efficiencies obtained for optimized waveform and 1-tone signals are compared and will be discussed. The algorithm presented in Fig. 12 is also used to characterize the maximum DC output (voltage and efficiency) by optimizing the waveform. For $3 \mathrm{k} \Omega$ and small RF power levels from -30 to $12 \mathrm{dBm}$, the optimized waveform gives more DC voltage compared to 1-tone signal. On the other hand, there is no improvement in the power range from -12 to $0 \mathrm{dBm}$. Meanwhile, for $100 \mathrm{k} \Omega$, the improvement is obtained over the entire power range. The maximum improvement is obtained around $-15 \mathrm{dBm}$. Indeed, the efficiency becomes equal to 74.7 $\%$ with the optimized waveform whereas it was only of $8.3 \%$ with the 1-tone signal. Fig. 19 shows the voltage/efficiency gain of optimized RF pulse signal compared to $\mathrm{CW}$, for 3 and $100 \mathrm{k} \Omega$. As can be seen, the gain at $3 \mathrm{k} \Omega$ has the maximum value of $4 \mathrm{~dB}$ at $-30 \mathrm{dBm}$. The gain decreases as the RF power increases. From $-12 \mathrm{dBm}$, the gain is approximately $0 \mathrm{~dB}$, which means there is no improvement between RF pulse signal and $\mathrm{CW}$. For $100 \mathrm{k} \Omega$, the gain is significantly higher with lowest gain of $4 \mathrm{~dB}$ at $0 \mathrm{dBm}$. The gain is $5.7 \mathrm{~dB}$ at -30 $\mathrm{dBm}$ and it increases to the highest value of $10.4 \mathrm{~dB}$ at -20 $\mathrm{dBm}$, then decreases as the RF power increases.

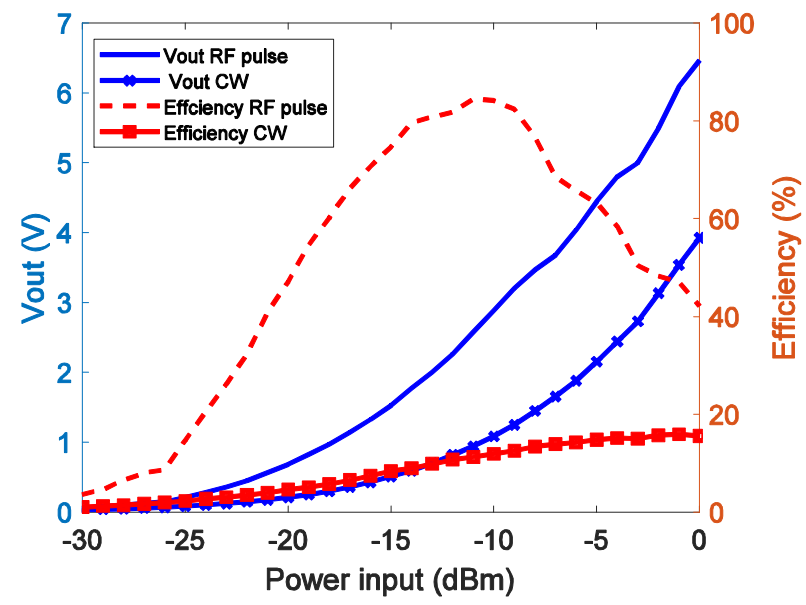

Fig. 19. Voltage/efficiency gain of RF pulse signal against RF power level, for different loads ( 3 and $100 \mathrm{k} \Omega$ ).

\section{CONCLUSION}

This paper reports a broadband rectenna optimized to operate from 1.6 to $2.8 \mathrm{GHz}$ and its performances under the RF-pulse optimized waveform compared to the ordinary $\mathrm{CW}$ signal. Optimization process is applied to find the optimum duty cycle as well as modulation frequency of the RF pulse signal for each carrier frequency, RF power level and output load. The measurements at two different load values show that the RF pulse signal's output DC voltage and efficiency are better than that of $\mathrm{CW}$ regardless of the carrier frequency. Five levels of RF power from -30 to $-10 \mathrm{dBm}$ are applied at the input of the rectenna. The highest voltage gain recorded at 3 $\mathrm{k} \Omega$ is $7.932 \mathrm{~dB}$ at $1.675 \mathrm{GHz}$ and $8.275 \mathrm{~dB}$ at $2.725 \mathrm{GHz}$, for $25 \mathrm{dBm}$ and $-20 \mathrm{dBm}$ RF power, respectively. Meanwhile, at higher load value of $100 \mathrm{k} \Omega$, the highest gain is $13.95 \mathrm{~dB}$ at $1.675 \mathrm{GHz}$ and the lowest gain in this case is $0.85 \mathrm{~dB}$ at 1.925 $\mathrm{GHz}$, for $-20 \mathrm{dBm}$ of RF power level. At such small RF power levels, the power gains are significant regardless of the frequency and they are particularly improved for frequencies 
below $1.8 \mathrm{GHz}$ and those above $2.6 \mathrm{GHz}$. It satisfies the demand of improving the rectenna performance at low power levels as well as at high load values. The proposed wideband rectenna excited by RF pulse signal has huge improvement compared to original CW for WPT applications.

\section{REFERENCES}

[1] A. Collado, and A. Georgiadis, "Optimal Waveforms for Efficient Wireless Power Transmission," IEEE microwave and wireless components letters, vol. 24, no. 5, May 2014

[2] A. Boaventura, D. Belo, R. Fernandes, A. Collado, A. Georgiadis and N. B. Carvalho, "Boosting the Efficiency: Unconventional Waveform Design for Efficient Wireless Power Transfer," in IEEE Microwave Magazine, vol. 16, no. 3, pp. 87-96, April 2015, doi: 10.1109/MMM.2014.2388332.

[3] N. Shariati, J. R. Scott, D. Schreurs and K. Ghorbani, "Multitone Excitation Analysis in RF Energy Harvesters-Considerations and Limitations," in IEEE Internet of Things Journal, vol. 5, no. 4, pp. 28042816, Aug. 2018.

[4] Alrio Soares Boaventura and Nuno Borges Carvalho "Maximizing DC Power in Energy Harvesting Circuits Using Multisine Excitation," In Microwave Symposium Digest (MTT), 2011 IEEE MTT-S International (pp. 1-4). IEEE.

[5] C. R. Valenta and G. D. Durgin, "Rectenna performance under poweroptimized waveform excitation," 2013 IEEE International Conference on RFID (RFID), Penang, 2013, pp. 237-244, doi: 10.1109/RFID.2013.6548160.

[6] Pham, Viet-Duc, Hakim Takhedmit, and Laurent Cirio. "Performance Improvement of a 2.4-GHz Multi-stage Rectifier Using Power Optimized Waveforms." 2018 25th IEEE International Conference on Electronics, Circuits and Systems (ICECS). IEEE, 2018.

[7] M. S. Trotter, J. D. Griffin and G. D. Durgin, "Power-optimized waveforms for improving the range and reliability of RFID systems," 2009 IEEE International Conference on RFID, Orlando, FL, 2009, pp 80-87, doi: 10.1109/RFID.2009.4911196.

[8] Hirakawa, Takashi, Ce Wang, and Naoki Shinohara. "RF-DC conversion efficiency improvement for microwave transmission with pulse modulation." Wireless Power Transfer 6.1 (2019): 57-66.

[9] Ibrahim, Rony, Damien Voyer, Mohamad El Zoghbi, Julien Huillery, Arnaud Bréard, Christian Vollaire, Bruno Allard, and Youssef Zaatar "Novel design for a rectenna to collect pulse waves at $2.4 \mathrm{GHz}$." IEEE Transactions on Microwave Theory and Techniques 66, no. 1 (2017): 357-365.

[10] Lo, Chun-Chih, Yu-Lin Yang, Chi-Lin Tsai, Chieh-Sen Lee, and ChinLung Yang. "Novel wireless impulsive power transmission to enhance the conversion efficiency for low input power." In 2011 IEEE MTT-S International Microwave Workshop Series on Innovative Wireless Power Transmission: Technologies, Systems, and Applications, pp. 55 58. IEEE, 2011

[11] N. Kuo and A. M. Niknejad, "RF-Powered-Tag Intermodulation Uplink With Three-Tone Transmitter for Enhanced Uplink Power," in IEEE Journal of Radio Frequency Identification, vol. 3, no. 2, pp. 56-66, June 2019, doi: 10.1109/JRFID.2019.2892939.

[12] Mahfoudi, Hichem, Mohamed Tellache, and Hakim Takhedmit. "A wideband rectifier array on dual-polarized differential-feed fractal slotted ground antenna for RF energy harvesting." International Journal of RF and Microwave Computer-Aided Engineering 29.8 (2019): e21775.

[13] K. Bhatt, S. Kumar, P. Kumar and C. C. Tripathi, "Highly Efficient 2.4 and $5.8 \mathrm{GHz}$ Dual-Band Rectenna for Energy Harvesting Applications," in IEEE Antennas and Wireless Propagation Letters, vol. 18, no. 12, pp. 2637-2641, Dec. 2019.

[14] S. Khang, D. Lee, I. Hwang, T. Yeo and J. Yu, "Microwave Power Transfer With Optimal Number of Rectenna Arrays for Midrange Applications," in IEEE Antennas and Wireless Propagation Letters, vol. 17, no. 1, pp. 155-159, Jan. 2018.
[15] U. Olgun, C. Chen and J. L. Volakis, "Investigation of Rectenna Array Configurations for Enhanced RF Power Harvesting," in IEEE Antennas and Wireless Propagation Letters, vol. 10, pp. 262-265, 2011.

[16] S. Shen, C. Chiu and R. D. Murch, "A Dual-Port Triple-Band L-Probe Microstrip Patch Rectenna for Ambient RF Energy Harvesting," in IEEE Antennas and Wireless Propagation Letters, vol. 16, pp. 3071-3074, 2017, doi: 10.1109/LAWP.2017.2761397.

[17] J. Antonio Estrada et al., "RF-Harvesting Tightly Coupled Rectenna Array Tee-Shirt With Greater Than Octave Bandwidth," in IEEE Transactions on Microwave Theory and Techniques, vol. 68, no. 9, pp. 3908-3919, Sept. 2020, doi: 10.1109/TMTT.2020.2988688.

[18] M. Wagih, O. Cetinkaya, B. Zaghari, A. S. Weddell and S. Beeby, "Real-World Performance of Sub-1 GHz and 2.4 GHz Textile Antennas for RF-Powered Body Area Networks," in IEEE Access, vol. 8, pp. 133746-133756, 2020, doi: 10.1109/ACCESS.2020.3011603.

[19] Y. Cao, X. Hui and E. C. Kan, "An RF-to-DC Rectifier Based on Tunable Threshold Diodes," in IEEE Journal of Radio Frequency Identification, vol. 3, no. 3, pp. 173-182, Sept. 2019, doi: 10.1109/JRFID.2019.2903923.

[20] M. Nie, X. Yang, G. Tan and B. Han, "A Compact 2.45-GHz Broadband Rectenna Using Grounded Coplanar Waveguide," in IEEE Antennas and Wireless Propagation Letters, vol. 14, pp. 986-989, Dec. 2015.

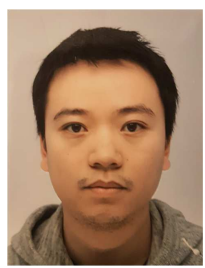

Viet-Duc Pham received his Engineer degree in electronics from Hanoi University of Science and Technology (Vietnam), in 2014, and his Master degree at the field of Microtechnology for communication systems and sensors from Gustave-Eiffel University (France), in 2016. He is currently working as $\mathrm{PhD}$ candidate at ESYCOM laboratory, Gustave-Eiffel University. His research interests include RF energy harvesting devices and power optimized waveforms for WPT.

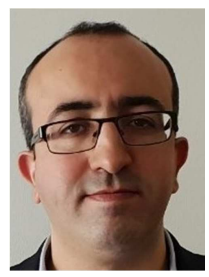

Hakim Takhedmit received the state engineer degree in electronics from the Ecole Nationale Polytechnique d'Alger (Algeria) in 2005 and his $\mathrm{PhD}$ degree in electrical engineering from the Ecole Centrale de Lyon (France) in 2010. His PhD dissertation dealt with the design and 3D modeling by the FDTD (Finite Difference Time domain) method of circuits and devices for wireless power transfer (WPT). He joined the ESYCOM laboratory, CNRS UMR 9007, in 2010 and worked as research assistant until 2013. He is currently associate professor at the University Gustave Eiffel (France). His research focuses on the design, the modeling and the experiments of antennas and circuits for RFID, energy harvesting, wireless power transfer in near-field and far-field. He is also working on the power optimization of waveforms for the WPT but also for SWIPT (Simultaneous Wireless Information and Power Transfer) systems.

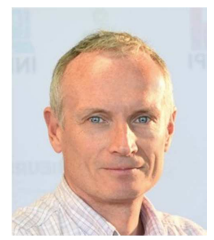

Laurent Cirio received the $\mathrm{PhD}$ degree in electronics from the Laboratoire d'Electronique, Antennes et Télécommunications (LEAT), university of Nice-Sophia Antipolis, France, in 1994. In 1996, he joined the ESYCOM laboratory (CNRS UMR 9007) at the university Gustave Eiffel. He is currently a full Professor and he is responsible for a training of engineers in apprenticeship in electronics and computer science at ESIPE, a public engineering school at the university Gustave Eiffel. His main research interest is focused on low-level energy harvesting using high frequencies electromagnetic waves. It includes developments of rectifying antenna and optimized waveforms applied for low level wireless energy transfer. 